\title{
TANKA E O SENTIMENTO DOS JAPONESES
}

\author{
Kensuke Tamai \\ Palestra proferida em 22 de \\ outubro de 1985, no Centro \\ de Estudos Nipo-Brasileiros
}

Meu tema de hoje: "Tanka e o sentimento dos japoneses" é um tema um tanto vago, mas o que vou falar hoje, seria, em resumo, qual o papel que o tanka veio desempenhando na sociedade japonesa, e também, qual o papel que ele desempenha atualmente. Como o sr. Nojiri vai proferir depois sobre a história do próprio tanka e do haicai, originário do tanka e ainda mais curto do que esse, aqui vou dizer apenas que o tanka é um poema curto japonês de 31 silabas distribuídas em 5 7-5 - $7-7$ silabas.

Os livros históricos antigos do Japão do começo do século VIII registram que o tanka mais antigo é de autoria do deus chamado Susanoonomikoto:

\section{YAKUMOTATSU IZUMOYAEGAKI TSUMAGOMENI \\ YAEGAKITSUKURU SONOYAEGAKIO}

Como as espessas nuvens que crescem,

no país de Izumo, construo os múltiplos cercados ao redor da casa, onde irei alojar minha esposa,

construo os múltiplos cercados ${ }^{(1)}$.

Este Susanoonomikoto é a divinização do mundo das trevas do subsolo, doenças, violências e vendavais. $O$ fato de ele ter composto o primeiro tanka e justamente um poema de amor, me parece que os japoneses pensavam que o tanka não era exclusivo das pessoas meigas, mas também, até deus do mal, como Susanoo podia compor, ou seja, sendo ser humano, qualquer um podia compor tanka, e ainda, a alma humana podia se tornar meiga pelo ato de compô-lo.

$\mathrm{Na}$ metade do século VIII, é compilada a antologia Manyôshû e nela estão contidos 4.516 poemas que foram compostos e transmitidos oralmente há 450 anos. Dentre os quais 4.208 poemas que correspondem a $93 \%$ do total pertencem ao estilo tanka. Aproximadamente a sua metade é de autcria desconhecida mas os 530 autores restantes pertencem a uma gama variada de camada social que vão desde impe-

(1) Todos os poemas foram traduzidos literalmente, apenas para transmitir a idéia geral. 
radores, nobres, guerreiros, agricultores, pescadores, prostitutas até mendigos. Com isto, os senhores podem perceber o quanto já nessa época o tankca estava em voga. O Manyôshhû é considerado a maior antologia poética do mundo, pelo número de poemas compilados $\mathrm{e}$ seus autores e da grande variação de camada social.

O Manyôsh û contém poemas sobre a beleza da natureza e tristeza da separação ou da morte, mas dentre eles, o poema de amor corresponde a $42 \%$. Os mais interessantes dentre esses são o poema da declaração de amor e da sua resposta. Vamos citar apenas um exemplo. O autor do poema, Ôtsunomiko, foi envolvido numa disputa política e obrigado a se suicidar aos 24 anos. Ele ofertou o seguinte tanka de amor a certa jovem:

\section{ASHIHIKINO YAMANOSHIZUKUNI IMOMATSUTO}

WARET ACHINURENU YAMANOSHIZUKUNI

Nos orvalhos da montanha,

banhei-me à espera de ti, nos orvalhos da montanha

O poema-resposta dessa jovem foi:

\section{AOMATSUTO KIMIGANUREKEMU ASHIHIKINO}

\section{YAMANOSHIZUKUNI NARIMASHIMONOO}

Nos orvalhos da montanha,

em que tu te banhaste à espera de mim, desejo de me tornar esses orvalhos

Nessa época, era comum declarar amor através de tanka e sua resposta também deveria ser dada em tanka. Ouvindo esses dois poemas, os senhores poderão notar que o poema da jovem declara o seu amor, utilizando habilmente as palavras contidas no poema de Ôtsunomiko. É essa a profundidade do amor contida no tanka.

Após o Manyôsh û, em 905, foi compilado o Kokinwakash $\hat{u}$ sob a ordem do Imperador e desde então, aproximadamente durante 500 anos, até 1435, foram compiladas 21 antologias poéticas sob ordem imperial, sendo a honra máxima como poeta (kajin) ser um dos escolhidos. Neste Kokinsh $\hat{u}$ estão compilados 1.100 poemas, mas excetuando-se 10, todo o resto pertence ao estilo tanka. Nesta época, o tanka já havia se tornado o principal estilo absoluto da poética japonesa.

Há um prefácio do seu compilador Kino Tsurayuki onde ele define o que é waka e o que é o belo. Este prefácio recebeu influências da estética de Shih Ching, obra chinesa produzida entre século XI e VI a.C. O referido prefácio justamente constitui a primeira teoria literária do Japão que definiu o belo da literatura japonesa através do tanka e que posteriormente, durante vários séculos, até a segunda metade do século XIX, foi a estrela de Belém das Letras japonesas. 
$\mathrm{E}$ com isso, os senhores poderão notar o quanto foi grande a força do tanka na Arte japonesa.

Há cerca de 10 anos, a UNESCO selecionou os 100 maiores artistas do mundo inteiro. Dentre esses, do Japão foi escolhida apenas a Murasaki Shikibu, autora de Genji Monogatari, que viveu entre fim do século X e começo do XI. Este Genji Monogatari é um longo romance que narra as aventuras amorosas de Hikaru Genji, um nobre famoso e homem ideal, e em que aparecem mais de 400 personagens. $\mathrm{O}$ orientalista da Inglaterra, Arthur David Waley, traduziu para o inglês consumindo 10 anos, desde 1923 a 1933, influenciando grandemente os estudos sobre o Japão desenvolvidos no Ocidente. No Genji Monogatari encontramos 1.001 tanka que estão inseridos em vários trechos de extrema importância, constituindo uma espécie de utamonogatari (narrativa poética). Assim, o tanka ocupava uma importante posição a este ponto, mesmo dentro do gênero da narrativa no Japão.

O personagem Hikaru Genji é o modelo ideal de homem da época. As condições para tanto, logicamente deveria ser formoso, mas além disso, deveria também preencher plenamente as seguintes condições: ser perito em literatura clássica chinesa e em caligrafia, ter dons musicais, ou seja, saber tocar koto ${ }^{(2)}$ e ser um exímio poeta.

Atualmente, o silabário japonês que corresponde ao $\mathrm{A}, \mathrm{B}, \mathrm{C}$ do alfabeto do português é o GOJÛON'HYÔ (silabário de 50 sons: $A, I$, $U, E, O, K A, K I, K U, K E, K O$ etc.) mas este começou a ser usado depois de 1880, inclusive para ordenar a distribuição das palavras no dicionário. Até então, geralmente usava-se a ordem de " $I-R O-H A$ - NI - HO - HE - TO " Este "I - RO - HA - NI - HO - HE TO "é um imayô, poema constituído de 4 versos com 7 e 5 silabas, que pertence à época de transição do chôka ${ }^{(3)}$ para tanka. Foi composto na segunda metade do século XII e versa sobre a efemeridade da vida sob o ponto de vista budista:

\section{IROHANIHOHETO CHIRINURUO \\ WAGAYOTAREZO TSUNENARAMU \\ UINO OKUYAMA KEFU KOETE \\ ASAKIYUMEMISHI YOHIMOSEZU}

A vida nos apresenta momentos de esplendor e de decadência, nela ninguém permanecendo imutável, transpondo a efemeridade do momento, não há nem o sonho fugaz, nem embriaguez

Neste poema, cada som é diferente do outro, não havendo nenhuma repetição de um mesmo som. Acredito que dentre os dicionários

(2) koto - denominação genérica de instrumentos de corda.

(3) choka - poema longo constitufdo de vários versos de 5 e 7 sílabas, terminando com 7 e 7 silabas. 
do mundo, o Japão tenha sido único país a utilizar um poema para ordenar palavras do dicionário.

$\mathrm{E}$ como prova de que atualmente o tanka ainda subsiste na vida dos japoneses, podemos citar o seu hino nacional. $O$ hino japonês foi tocado pela primeira vez no aniversário do Imperador Meiji, em 1880, e instituído como hino nacional em 1893. Sua letra é um tanka que resultou de modificəções efetuadas no século XVI em cima de um poema de autor desconhecido, que aparece no anteriormente referido Kokinsh $\hat{u}$ :

\section{KIMIGAYOWA CHIYONI YACHIYONI SAZAREISHINO IWAOTO NARITE KOKENO MUSUMADE}

Que sejam vossos dez mil anos de reinado feliz

Governai, meu senhor, até que os que agora são seixos, Transformem-se, unidos pelas idades, em rochedos poderosos Cujos lados veneráveis o musgo cobre ${ }^{(4)}$

Esta letra foi usada na sua integra como hino nacional japonês e segundo o Guiness Book, é o mais curto hino nacional do mundo. Apenas como informação, o hino mais longo infelizmente não é o do Brasil, mas da Grécia.

Atualmente, uma parte do povo japonês combate fortemente o Kimigayo, alegando ser uma exaltação do imperador, ter uma forte coloração de imperialismo japonês, mas acredito que continuará sendo cantado como hino nacional.

Citei anteriormente que o tank $\alpha$ desempenha um importante papel na expressão de amor dos japoneses, mas por outro lado, ele veio desempenhando papel semelhante com relação à morte. Isto porque os japoneses compõem jisei (poema de despedida com a aproximação da morte), não só quando morrem por doença ou morte natural, mas também nos casos de execução de pena de morte e, principalmente, no suicídio por seppuku (haraquiri). Podemos citar vários exemplos antigos, mas o Yukio Mishima, escritor muito conhecido dos senhores, que se suicidou por seppuku em 1970 aos 45 anos, no dia do seu suicidio compôs um tanka que em comparação ao resto de suas obras, julgo ser muito infantil:

\section{CHIRUO ITOHU YONIMO HITONIMO SAKIGAKETE}

CHIRUKOSOHANATO FUKUSAYOARASHI

Morrer - à frente das pessoas e do mundo

que temem o fim da vida -

é como o despetalar numa tempestade

(4) Esta tradução é conforme F'atos sobre o Japão, de junho/77 publicado pelo Consulado do Japão. 
Basicamente o tanka é uma literatura, mas por outro lado, não podemos negar que os tanka foram utilizados em cerimônias, em convivência social e ainda, na política, devido à sua força de apelar aos sentimentos humanos por possuir bela musicalidade e conteúdo conciso numa composição poética curta. é também verdade que durante a Segunda Guerra Mundial, os grandes poetas, a pedidos (do governo) compuseram tanka a favor da guerra, que se hoje analisarmos, seria motivo de vergonha.

O Imperador Meiji compôs cerca de 100.000 tanka nos seus 60 anos de vida. Mais do que expressar o sentimento do próprio imperador, esses poemas foram usados pelos políticos para fortalecer o sistema imperial e como meio de induzir o povo à moral feudal.

Em 1910, o governo, para abafar um movimento progressista emergente na época, tramou um atentado contra o Imperador, prendeu socialistas e anarquistas, realizou julgamentos secretos, condenando 12 pessoas à pena de morte e mais 12 à prisão perpétua. E o governo atribuiu a autoria do seguinte poema ao Imperador Meiji para fazer com que ele se livrasse da responsabilidade moral como mandante do incidente, conseguindo o efeito desejado:

\section{TSUMIARABA WAREOTOGAMEYO AMATSUKAMI}

\section{TAMIWA WAGAMINO UMISHIKONAREBA}

Se há algum crime, oh divindades,

repreendei-me,

pois o povo faz parte do meu ser

Atualmente no Japão, o tanka está muito em voga juntamente com o haicai. Dizem que o número de poetas (kajin) atinge 5.000 .000 de pessoas, que há mais de 430 entidades entre grande e pequeno porte, em torno de revistas especializadas, e que mesmo os poetas profissionais deve transpor facilmente a casa dos 1.000. Mesmo no Brasil, há mais de 120 poetas em torno de Yashiju, única revista de orientação ao tank $\alpha$. Além disso, dizem que há aproximadamente 100 poetas que publicam nos 3 jornais da colônia, concluindo-se que há cerca de 220 - 230 poetas no total. Todos eles compõem ao menos alguns poemas por mês, algumas dezenas por ano. Então, quantos tanka estão sendo produzidos no mundo inteiro?

Shiki Masaoka é um literato que morreu em 1902 aos 37 anos. Ele é considerado o orientador pioneiro dos tanka e haicai modernos, e que deu vida nova a esse estilo que estava em decadência na segunda metade do século XVIII e início do XIX. Certo dia, já à beira da morte, ele reuniu seus discípulos e disse: "Nós estamos dando a vida pelo tanka e haicai. Mas o tanka é composto de apenas 31 sílabas distribuídas em $5-7-5-7-7$ e o haicai, ainda mais curto, de 17 sílabas em $5 \quad 7 \quad 5$. Assim sendo, acabando de utilizar todos os sons da língua japonesa, um dia, não haverá mais produção de novos haicais e gradativamente, os tanka e os haicais desaparecerão" Então eu 
pedi para um conhecido meu verificar no computador, o número de combinatória em $5-7-5$ dos 50 sons do japonês. O resultado foi: 385.625.479.490.433.329.095.458.984.375 (385 octilhões, 625 septilhões, 479 sextilhões, 490 quintilhões, 433 quatrilhões, 329 trilhões, 095 bilhões, 458 milhões, 984 mil e 375 ) - um número de 30 casas. Isso, em se tratando de haicai de apenas $5-7$ - 5 sílabas. Como seria nos tanka que ainda são acrescidos de mais 7 e 7 silabas: talvez resultasse um número com centenas, ou melhor, milhares de casas. Portanto, senhores, componham os tanka sem se preocuparem.

Traduzido por:

HELENA HISAKO TOIDA 